\title{
Needs of countries with longer timescale for deep geological repository implementation
}

\author{
Bálint Nős* \\ Strategical and Technical Directorate, PURAM, HRSZ.: 8803/2, 7031 Paks, Hungary
}

Received: 12 March 2019 / Accepted: 16 September 2019

\begin{abstract}
Countries operating nuclear power plants have to deal with the tasks connected to spent fuel and high-level radioactive waste management. There is international consensus that, at this time, deep geological disposal represents the safest and most sustainable option as the end point of the management of high-level waste and spent fuel considered as waste. There are countries with longer timescale for deep geological repository (DGR) implementation, meaning that the planned date of commissioning of their respective DGRs is around 2060. For these countries cooperation, knowledge transfer, participation in RD\&D programmes (like EURAD) and adaptation of good international practice could help in implementing their own programmes. In the paper the challenges and needs of a country with longer implementation timescale for DGR will be introduced through the example of Hungary.
\end{abstract}

\section{Introduction and background}

\subsection{Countries with longer implementation timescale}

Nuclear Power Plants are operated since 1970s and 1980s in Central and Eastern European (CEE) countries. This means that these countries have to deal with spent fuel management, including the final disposal of high-level radioactive waste (HLW): spent nuclear fuel or vitrified HLW corresponding to the direct disposal or reprocessing option, respectively, for the back-end of the nuclear fuel cycle. As it is formulated in the Council Directive 2011/70/ EURATOM (Directive) [1]: "it is broadly accepted at the technical level that, at this time, deep geological disposal represents the safest and most sustainable option as the end point of the management of high-level waste and spent fuel considered as waste."

Taking into account the above mentioned, most of the CEE countries have to face the challenge of implementing a deep geological repository, the programs for which are in an early stage, so these countries could be named as: "countries with longer timescale for deep geological repository implementation" (countries with longer implementation timescale). Usually the planned commissioning date for deep geological repositories (DGRs) in these countries is around 2055-2065 (see Fig. 1).

Nevertheless, when a country is in an early stage of implementation, it is essentially important from several aspects (and it is required by the Directive [1]), to develop a

\footnotetext{
* e-mail: balint.nos@rhk.hu
}

long-term programme - and an underpinning RD\&D plan - for the implementation of a DGR. A long-term programme, with its technical contents and connected cost calculations is necessary to collect enough funding for the long-term liabilities, meeting the general principle that requires not leaving undue burden on future generations.

\subsection{The need for cooperation and assistance}

Because of the small scale of the nuclear industry including radioactive waste management - in CEE countries, providing the necessary resources (human, technical, financial, etc.) for deep geological repository implementation through decades could be more challenging. Very useful guidance documents exist to assist Member States in the development of their long-term programme and the connected RD\&D plan.

The NAPRO working group of the European Nuclear Energy Forum has drafted a guide (NAPRO Guide [3]) with the aim of assisting the Member States in the establishment of their National Programmes, addressing among others guidance on how to develop a comprehensive programme for all waste streams, showing the management routes from the generation until the final disposal in dedicated repositories. From all waste streams, the biggest challenge is to find a management route and implement the programme for the disposal of HLW and spent nuclear fuel.

The Directive [1] prescribes that, "the National Programmes shall include (...) the research, development and demonstration activities that are needed in order to 


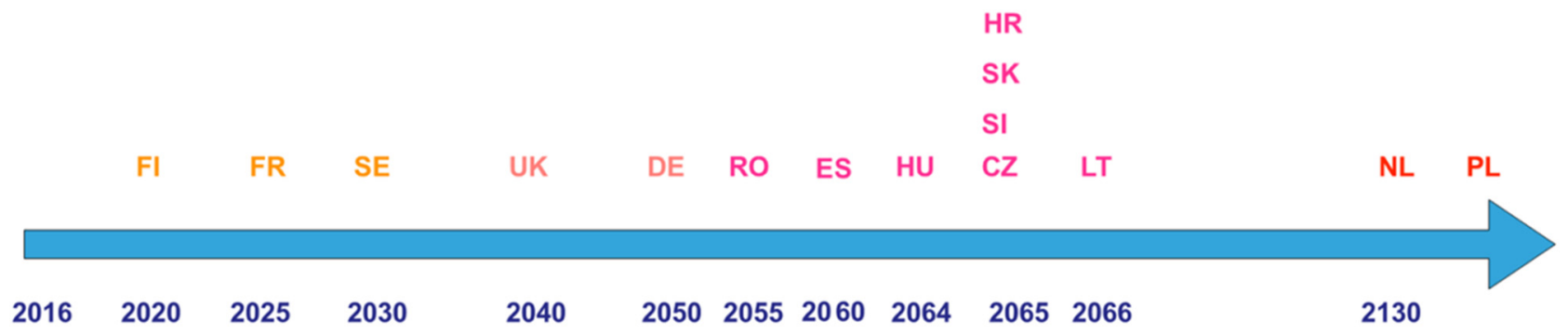

Fig. 1. Planned start of operation of deep geological facilities in the EU [2].

implement solutions for the management of spent fuel and radioactive waste". The NAPRO Guide [3] contains some general guidance on how to meet this requirement. More specific assistance on RD\&D planning can be found in the PLANDIS Guide [4], which was developed by the SecIGD2 Project. The PLANDIS Guide was intentionally focused on the needs of the countries with longer implementation timescale (or countries with less-advanced programmes).

Cooperation at the international level can assist these countries in facing some of these challenges. Some of the CEE countries follow the so-called "dual track approach", meaning that they are considering the possibility of shared solutions for disposal either as a preferred or as an alternative option. From the technical and financial point of view, the shared disposal option is a rational idea to solve the problems, however, beside the technical issues, more complex legal, financial and political questions have to be answered.

Another important circumstance is the fact that there are countries with mature, advanced DGR implementation programmes. These countries accumulated a vast amount of information and experience during the past few decades. This knowledge base could be adapted by countries with longer implementation timescale for their own situations, within their boundary conditions. In this respect, the EURAD project (European Joint Programme on Radioactive Waste Management) could play an important role in collecting the state of knowledge and developing training modules in different areas.

In the next chapters, the example of Hungary is used to illustrate the specific boundary conditions, current situation of a programme and $\mathrm{R} \& \mathrm{D}$ needs of a country with longer implementation timescale.

\section{Programme boundary conditions}

\subsection{National policy}

The Hungarian Parliament, in accordance with the requirements of the Directive, adopted the national policy document on the management of spent nuclear fuel and radioactive waste (national policy). The national policy summarizes the principles applicable to the management of spent nuclear fuel and radioactive waste. Most of these principles were promulgated in the Hungarian legal regulation - mainly in the Act CXVI of 1996 on nuclear energy (Atomic Act) and its implementing decrees - before the adoption of a national policy, but have also been recast according to the requirements of the Directive in a systematic manner. Some of the important principles from the national policy - which are relevant for the DGR implementation programme - are highlighted below:

- during the use of atomic energy, safety has priority over any other aspects;

- the Hungarian state shall assume ultimate responsibility for the management of spent fuel and radioactive waste generated in Hungary (with some special exemptions for spent sealed radiation sources and research reactor spent nuclear fuel);

- the primary responsibility for safety rests with the license holder of the facility or activity;

- during the use of atomic energy, the safe final disposal of the generated radioactive wastes and spent nuclear fuel shall be provided in line with the latest justified scientific results and the international recommendations and experience in such a way that no undue burden is transferred to future generations.

According to the national policy, the final decision concerning the back-end of the fuel cycle of power reactors is not yet necessary to be made, but it is important to state that the country must address the management of highlevel radioactive waste regardless of the chosen back-end option. The most suitable and most widely accepted solution to this is final disposal in a deep geological disposal facility. The policy concerning the back-end of the fuel cycle follows the "do and see" principle, meaning that an open fuel cycle i.e. direct, domestic disposal of spent fuel originating from nuclear power plants has been determined as the reference scenario, which provides the basis of the relevant cost estimates concerning the currently operating four units. Domestic and international developments concerning the back-end of the fuel cycle must be followed ("see") and, if necessary, must be incorporated into the policy of the back-end of the fuel cycle, while at the same time progress must be made on the site selection of the domestic deep geological disposal facility ("do" [5]).

\subsection{National framework}

The Hungarian Atomic Energy Authority (HAEA) was established in Hungary, as an independent regulatory body, responsible for the supervision and licensing of nuclear facilities and radioactive waste repositories, from nuclear safety, radiation protection and physical protection point of view. 


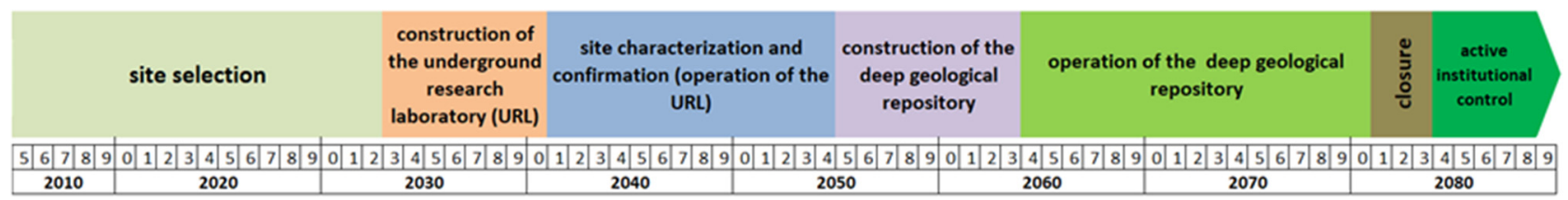

Fig. 2. Time schedule of the Hungarian DGR implementation programme.

In accordance with the Atomic Act, the Hungarian government appoints an organization to carry out the tasks related to

- the preparation of the national policy and national programme;

- the final disposal of radioactive waste;

- the interim storage of spent fuel and the back-end of the nuclear fuel cycle;

- the decommissioning of nuclear facilities.

In 1998, the legal predecessor of Public Limited Company for Radioactive Waste Management (PURAM) - the waste management organization of Hungary - was established to cover the above mentioned tasks and responsibilities.

On the basis of the Atomic Act, a segregated state financial fund, the Central Nuclear Financial Fund (Fund) was created in 1998. This provides funding for the management of radioactive waste and spent fuel, and for the tasks related to the decommissioning of nuclear facilities. The costs of managing spent fuel and radioactive waste are to be borne by those who produced these materials - through making payments into the Fund.

\subsection{Main milestones of DGR implementation}

The national programme of Hungary for spent nuclear fuel and radioactive waste management was adopted by the Hungarian government. At the level of the national programme, the coherence and interrelations between the management of the different waste streams were taken into account, and the main milestones of DGR implementation were set.

After consecutive phases of surface-based investigations (see Fig. 2), the site is selected and an underground research laboratory is planned to be constructed from 2032 at that site. During the operation of the URL, the in situ underground investigation, site confirmation activities will take place in the first period, while in the second period, the focus will move to the demonstration programs with the aim of preparing the construction and operation. The start of the construction of the DGR is scheduled for 2055 and the operation for 2064.

The first conceptual plan [6] describing the disposal system of the DGR was developed in 2005. This plan contained the first cost calculations of the whole programme. In 2008, the technical and financial update of the long-term investigation programme of the Boda Claystone Formation [7] was compiled. In principle the time schedule of the implementation programme for the DGR and the cost estimate are based on this document. The long-term investigation programme was reviewed by the Swiss NAGRA, who had given useful comments on the document.

At this early stage of site selection, it is necessary also for countries with longer implementation timescale to develop a long-term implementation programme and a connected R\&D plan, in order to have an idea about the technical content and the cost implications of the project. This is important, because on the basis of the cost calculations enough money has to be collected in the fund during the operation of the NPPs. In the Hungarian cost profile, the deep geological disposal project is the most expensive element, so the technical content of the programme has to be justified, and the cost estimates have to be defendable.

Due to the very long timescale of the implementation of deep geological disposal programme, maintaining the core competences within a waste management organization and keeping educated, skilled and experienced workforce for decades could be a challenge mainly for countries with longer implementation timescale. Participation in international R\&D projects could be a good instrument to attract young people into the radioactive waste management business and this approach could be justified in those cases as well, when the results of a given R\&D task will be used much later in the national programme of the interested country.

\section{Development of a R\&D framework programme}

\subsection{Introduction}

In Hungary, the preparations for the disposal of spent nuclear fuel and HLW started in 1993. In 1994, an exploration tunnel was excavated in the Mecsek Uranium Mine, reaching the Boda Claystone Formation (BCF), and onsite underground data acquisition began at a depth of $\sim 1050 \mathrm{~m}$. The formation was explored underground by a tunnel extending into the claystone $\sim 500 \mathrm{~m}$. The tunnel was utilized as an Underground Research Laboratory (URL), and a large amount of onsite underground data was collected. During this programme, the Hungarian partners received technical assistance from the experts of the Canadian AECL company. In 1998, the mine was flooded, and the opportunity to perform underground investigations was terminated.

From 2000, based on desktop studies, a nationwide screening was carried out by evaluating the potential host rock formations in detail. Thirty-two lithological forma- 


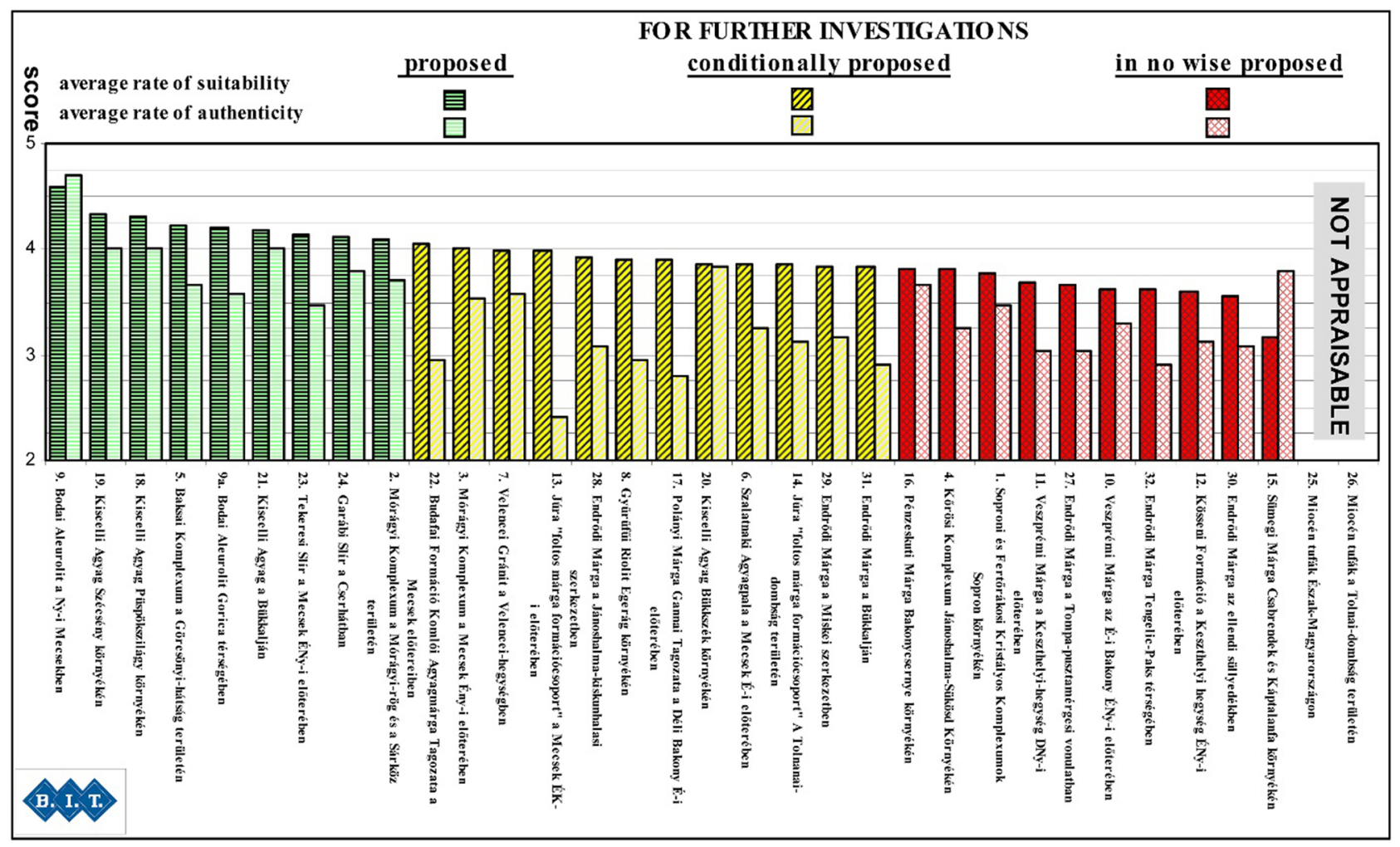

Fig 3. Ranking of the formations in Hungary during the screening 2000-2003.

tions potentially suitable for a deep geological repository, within the territory of Hungary, were identified (see Fig. 3). This comprehensive investigation in 2003 confirmed that the BCF has the highest potential among the suitable host rocks for hosting a DGR.

Between 2004 and 2017, there were two new starts for the investigations of the BCF, but both programmes were interrupted. This was a typical challenge of a small nuclear country: due to the lack of enough resources it was difficult to run three big programmes (continuous extension of the interim storage facility for spent fuel, construction of an underground repository for $\mathrm{L} / \mathrm{ILW}$ and site selection activities for a DGR) in parallel.

In 2018, PURAM drafted a new site investigation framework programme for the $\mathrm{BCF}$, based on the recently extended governmental decree, which now contains the requirements for the site selection phase. Both the modified regulation and the new framework programme seriously take into account the recommendations of the PLANDIS Guide [4].

In the development of the site investigation framework programme, PURAM could effectively use the methodological advices of the French waste management organization, ANDRA, which were transferred in the frame of a cooperation agreement between the companies. The cooperation agreement focused on project development planning and functional analyses. It should be emphasized that it was important for the colleagues of PURAM to understand the methodology, the rationale behind that and implement it within the Hungarian boundary conditions. The experts of ANDRA also promoted this kind of adaptation (instead of copying) and mentoring programme, which provided a real added value for PURAM from a country with longer implementation timescale.

\subsection{Structure of the site investigation framework programme}

The long-term safety of the disposal facility relies on multiple barriers (and multiple safety functions). In case of a deep geological repository, the host formation and the geological barrier play an extremely important role in meeting the post-closure safety targets. Accordingly, the site investigation framework programme has an independent annex for geological investigations. In the main text, meeting the regulatory requirements, the $R \& D$ activities are structured in the following areas:

- waste inventory - amount, activity content, physicalchemical form;

- waste package (waste form and package) - geometry, properties, long-term behaviour, compatibility with other elements of the disposal system;

- engineered barrier system (buffer, backfill, seals and plugs) - geometry, properties, long-term behaviour, compatibility with other elements of the disposal system; - geological and natural environment of the facility properties and long-term evolution of the geological barrier, external natural hazards relevant for the safety of the facility (this area is elaborated in detail in the 
Table 1. Main goals and durations of the surface-based investigation phases.

\begin{tabular}{lll}
\hline & Surface-based investigation & \\
\hline $\begin{array}{l}\text { Investigation phase I } \\
2019-2023\end{array}$ & $\begin{array}{l}\text { Investigation phase II } \\
2024-2029\end{array}$ & $\begin{array}{l}\text { Investigation phase III } \\
2030-2032\end{array}$ \\
\hline $\begin{array}{l}\text { General data acquisition in order } \\
\text { to rank candidate areas }\end{array}$ & $\begin{array}{l}\text { Site selection and characterization } \\
\text { of chosen site }\end{array}$ & Preparations of the URL \\
\hline
\end{tabular}

geological investigation programme, which is an independent annex of the framework programme);

- preliminary design and layout of the surface and underground part of the facility;

- operation of the facility, transport and transfer of waste packages, ensuring retrievability/reversibility;

- methods for R\&D investigations, models, evaluation;

- data management, and long-term information preservation.

\subsection{Phases of the site investigation framework programme}

The phases (see Tab. 1) of the R\&D activities for the surface-based investigation period (with site selection and preparations for the construction of the underground research laboratory) were defined based on the targets of the geological investigation program.

For each phase, a detailed site investigation plan has to be prepared by PURAM and has to be submitted for licensing to the regulatory body (HAEA). At the end of each phase, a final investigation report and on the basis of that a preliminary safety case has to be compiled, and the site investigation framework programme has to be reviewed and updated, if necessary, for the next phase(s). In this preliminary stage of the Hungarian Programme, the safety case is dominantly used (i) to help in understanding the main processes and how the elements of the systems could fulfil their safety functions; (ii) to identify the uncertainties and knowledge gaps, and (iii) through sensitivity analyses to prioritize the $R \& D$ needs.

\subsection{Investigation area}

An investigation area $\left(86.7 \mathrm{~km}^{2}\right)$ was identified for the site investigation framework programme in such a way that this contains all relevant field investigation locations within its boundary (see Fig. 4, green line). The surface projection of the potential disposal zone $\left(32.6 \mathrm{~km}^{2}\right)-$ the area, where the Boda Claystone Formation can be found at the depth between $500 \mathrm{~m}$ and $1000 \mathrm{~m}$ - is also shown on this map (Fig. 4, brown line).

The investigation area is important from the public participation point of view as well. In the licensing procedure for the site investigation framework programme and site investigation plan, a public hearing is organized by the HAEA. All interested people can participate and those who own a property within the investigation area have a "client right" in the licensing process.

\subsection{Goals of the investigation phases}

The general aim of the investigation phase $I$ is data acquisition for site characterization and ranking the candidate areas for phase II. Four special goals were identified for phase I:

- understanding of the geological environment in such detail that the ranking of the candidate areas can be made;

- evaluation of unfavourable site properties and exclusion criteria and screening out of those;

- detailed investigation of the host formation;

- data acquisition for the preliminary safety case.

Phase II of the investigations will focus on a reduced $10 \mathrm{~km}^{2}$ area. The general aim of investigation phase II is data acquisition for designating the location of the underground research laboratory. Special goals of investigation phase II are:

- designation and surface-based characterization of the site, confirmation of geological suitability;

- designation of the location of the surface and underground facilities and the underground research laboratory;

- data acquisition for the conceptual design of the facility;

- data acquisition for the preliminary safety case.

The general aim of investigation phase III is data acquisition and the preparation of the underground research laboratory and for the site licence application. Special goals of investigation phase III are:

- characterization of the geological environment of the previously designated location for the surface and underground parts of the facility in such details that the site licence application could be compiled;

- preparation of the underground research laboratory and planning the investigation program to be conducted in it; - evaluation of the reference state of the site for the environmental impact assessment;

- data acquisition for the safety case, substantiating the site licence application.

The field investigations of phase III are focused on a few $\mathrm{km}^{2}$ area of the site.

During the three above mentioned phases, in parallel with the geoscientific investigations, the relevant $R \& D$ activities have to be carried out for the different elements of the disposal system: waste inventory, waste form, packaging, engineered barrier system (buffer, backfill, seals and plugs). The preliminary conceptual design of the underground and surface facilities has to be developed. 


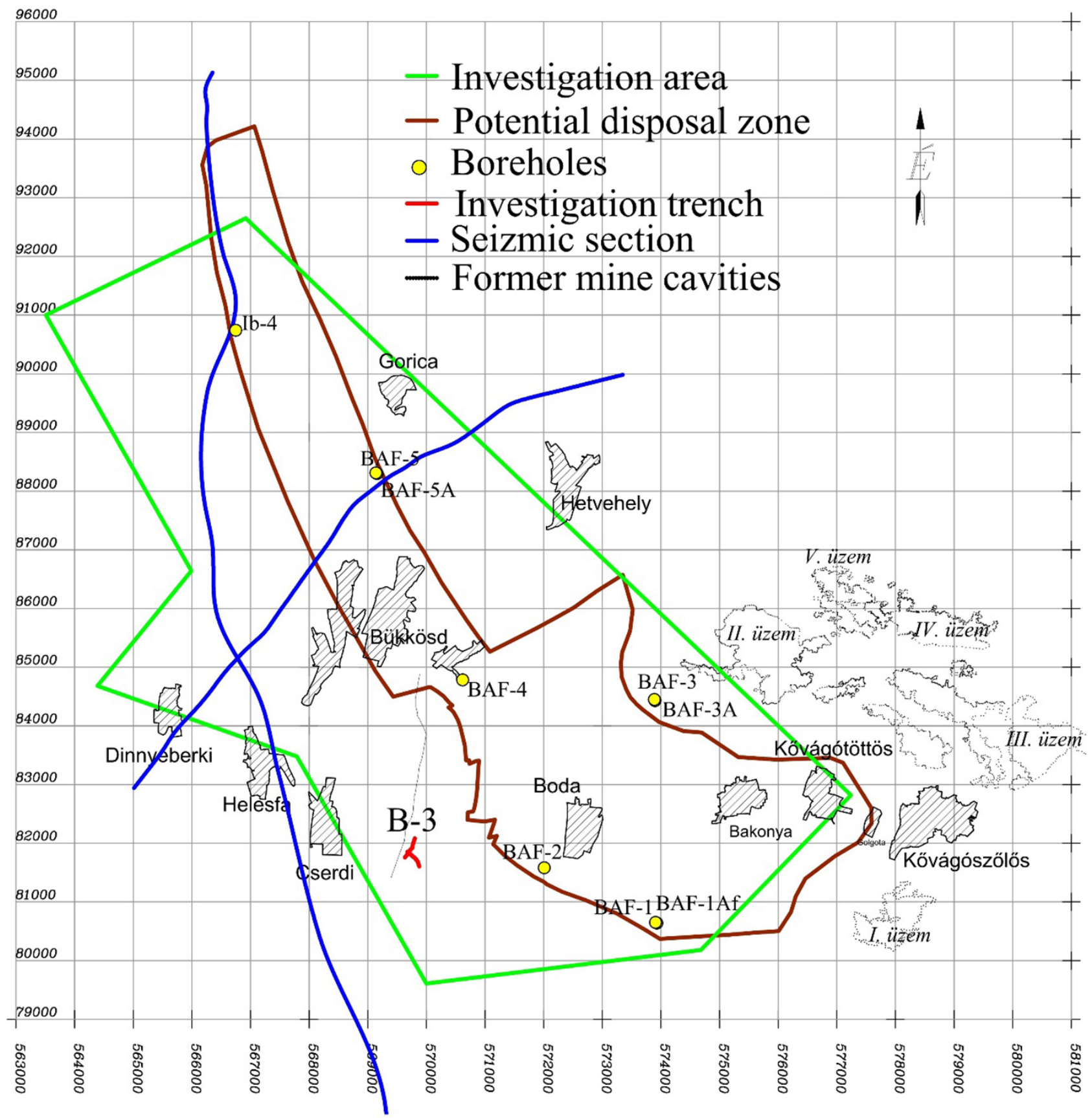

Fig. 4. Investigation area and potential disposal zone.

At the end of investigation phase III, an environmental protection licensing procedure (based on an environmental impact assessment) is considered for the construction and operation of the URL. From nuclear safety point of view, the site licensing procedure will be conducted. In the frame of this licensing step, mainly based on the safety case, the feasibility of the disposal concept is demonstrated. The decision in principle of the Hungarian Parliament - which is a requirement based on the Atomic Act - will be asked after the site licence is granted.

\section{Summary}

The execution of the implementation programme for a deep geological repository contains some challenges for countries with longer implementation timescale. There are a lot of preconditions for the success of implementation, like:

- high quality scientific and technical work;

- sound political commitment and support;

- adequate funding and financing scheme; 
- acceptance of the stakeholders (local people, general society);

- enough educated, skilled and experienced workforce with the necessary competencies covering several disciplines.

Nevertheless, for a country in the early stage of its programme, it is important to develop a long-term implementation programme, in which the milestones are set and clear decision points are defined. The technical content of the programme has to be justified, and the cost estimates have to be defendable. International benchmarking and validation can increase the credibility of the programme, which helps to gain acceptance of the stakeholders (public, regulatory body, politics, waste producers). International good practices can be adapted and incorporated within the given country's boundary conditions. At an early stage of the programme, lessons learned by advanced countries, the rationale (pro's and con's) behind strategical decisions (e.g. the URL is a part of the future DGR or not) and methodological recommendations have a real added value.

Participation in international RD\&D programmes (e.g. European Commission cofounded programmes, like EURAD) on one hand can support the knowledge transfer from advanced countries to the countries with longer implementation timescale, on the other hand, it is a good instrument to attract young people into the radioactive waste management business, which is necessary to providing educated, skilled and experienced workforce for decades.

\section{References}

1. Council Directive 2011/70/EURATOM of 19 July 2011 establishing a Community framework for the responsible and safe management of spent fuel and radioactive waste

2. COM (2017) 236 final, Report from the Commission to the Council and the European Parliament on progress of implementation of Council Directive 2011/70/EURATOM and an inventory of radioactive waste and spent fuel present in the Community's territory and the future prospects, Brussels, 2017

3. European Nuclear Energy Forum (ENEF), Work Group Risk; Working Group (NAPRO, National Programmes): Guidelines under the Council Directive 2011/70/ EURATOM of 19 July 2011 on the responsible and safe management of spent fuel and radioactive waste for the establishment and notification of National Programmes

4. T. Beattie, R. Kowe, J. Delay, G. Buckau, D. Diaconu, RD\&D Planning Towards Geological Disposal of Radioactive Waste, DELIVERABLE (D-N: 2.3), Guidance for less-advanced Programmes, 2015

5. Sixth National Report of Hungary prepared within the framework of the Joint Convention on the Safety of Spent Fuel Management and on the Safety of Radioactive Waste Management, 2017

6. F. Takáts et al., Preliminary conceptual plan and cost estimate for the deep geological repository accommodating the high level and long-lived wastes and spent nuclear fuel generated in Hungary, TS(R)6/25rev2., 2005 (available in Hungarian only)

7. L. Kovács et al., Technical and financial update of the longterm investigation program of the Boda Claystone Formation, 2008 (available in Hungarian only)

Cite this article as: Bálint Nôs, Needs of countries with longer timescale for deep geological repository implementation, EPJ Nuclear Sci. Technol. 6, 22 (2020) 